\title{
Diagnosis and treatment of penile injury: Ten years experience of an emergency department
}

\author{
Paolo Panella, Pietro Pepe, Michele Pennisi \\ Urology Unit, Cannizzaro Hospital, Catania, Italy.
}

\begin{abstract}
Summary Introduction: To evaluate the imaging accument of penile injury.

Materials and methods: From January 2010 to January 2020, 20 men (median age 40.2 years) were admitted to our Emergency Department with the diagnosis of penile injury; the penile trauma was related to sexual intercourse in 16 cases, masturbation in 3 cases and injury caused by the partner in 1 case. All the patients underwent accurate medical history, clinical examinations and diagnostic imaging. Color Doppler ultrasound (CDU) evaluation was performed by Logiq E9 ecograph (General Electric; Milwaukee, WI) supplied with a linear probe small (7.5-10 MHz); magnetic resonance image (MRI) examination was performed within 3-24 hours from the trauma using a 1.5 Tesla scanner, (ACHIEVA 3T; Philips Healthcare Best, the Netherlands) performing pre-contrast and post-contrast multi-planar turbo spin-echo T1 and T2-weighted sequences.

Results: 15/20 (75\%) men with high suspicion of the tunica albuginea rupture underwent surgical exploration; conversely, $5 / 20(25 \%)$ patients underwent conservative management. CDU detected 11/15 (73\%) fractures of the penis and in 8 of them the length of the rupture was underestimated (more than 5 millimeters). On the contrary, MRI diagnosed all the albuginea ruptures showed by surgical exploration, but underestimated the length of the lesions in 9/15 (60\%) cases.

The IIEF-5 score administered six months later penile trauma demonstrated a good performance in all the patients.

Conclusions: In our series, all the patients with a tunica albuginea rupture $<5 \mathrm{~mm}$. diagnosed by MRI were submitted to conservative management with a complete functional restitutio ad integrum.
\end{abstract}

KEY WORDS: Penile injury; MRI; CDU; Imaging and penile trauma.

Submitted 17 May 2020; Accepted 11 July 2020

\section{INTRODUCTION}

The injury of corpora cavernosa is a very rare urological emergency with an estimated incidence of 1.02/100,000 male subjects per year in the United States $(1,2)$; the rupture of the penis is secondary to an abrupt deviation during erection to which follows sudden pain and a noise referred as "crack" with rapid loss of erection combined with subcutaneous hematoma. The fractures of the penis following non-penetrating trauma are most commonly sustained during sexual intercourse; rarely, the trauma could be induced by careless movement performed to stop the erection (manuever of Taghaandan) or masturba- tion. The pain and sound are made by a strain in the tunica albuginea that during erection become thin from 2 to $0.25-0.50 \mathrm{~mm}$. reducing its elasticity and reaching, in case of rupture, an internal pressure of $1.500 \mathrm{mmHg}$ (2). The lesions of tunica albuginea could be unilateral or bilateral involving the corpus spongiosum of the urethra $(3,4)$. The clinical presentation is characterized by the presence of gross hematoma of the penis that, in the majority of the cases, is deviated controlaterally to site of rupture. The presence of "butterfly hematoma" suggest the injury of the Buck fascia $(4,5)$.

The diagnosis is usually based on clinical history (the typical sound referred as "crack") and clinical examination. In the presence of urethral injury the patient could refer urethral bleeding or hematuria combined with dysuria, urinary voiding symptoms and acute urinary retention. The diagnostic imaging is mandatory to evaluate the integrity of the tunica albuginea (site and length of the lesion) and the extension of the hematoma. Color doppler ultrasound (CDU) and magnetic resonance imaging (MRI) are highly recommended to evaluate the morphology of the penis to plan the best clinical management; CDU could underestimate the extension of corpora cavernosa lesion but it allow to easily evaluate the dorsal penis vascular complex. In this retrospective study, we report our experience regarding the role of imaging in the diagnosis and clinical management of patients with non-penetrating penile injury.

\section{MATERIALS AND METHOdS}

From January 2010 to January 2020, 20 men with median age of 40.2 years (range: $21-65$ ) were admitted to our Emergency Hospital for non-penetrating penile injury. The penile trauma was related to sexual intercourse in 16 cases, masturbation in 3 cases and injury caused by the partner in 1 case; the clinical presentation of the patients at hospital admission are listed in Table 1.

All the patients underwent clinical examination, CDU and MRI evaluation. Ultrasound examination was performed by a Logiq E9 ecograph (General Electric; Milwaukee, WI) supplied with a linear probe small $(7.5-10 \mathrm{MHz})$ to evaluate the integrity of the tunica albuginea and dorsal vascular complex of the penis, the site and extension of the hematoma. All MRI examinations were performed within 3-24 hours from the trauma using a 1.5 Tesla scanner, (ACHIEVA 3T; Philips Healthcare Best, the Netherlands) 
equipped with surface 32 channels phased-array coil placed around the pelvic area with the patient in the supine position. All patients were studied with pre-contrast and postcontrast multi-planar turbo spinecho T1- weighted and T2-weighted (T2W) sequences (Figure 1).

The 15/20 (75\%) men with high suspicion of penis rupture underwent surgical exploration; conversely, 5/20 (25\%) patients underwent conservative management. In all cases the length of the penis lesion was measured with a centimeter during surgery. All the patients underwent follow up 1, 3 and 6 months from the trauma performing clinical evaluation, CDU and, in selected cases, MRI of the penis; moreover, the International Index Erectile Function-5 score (IIEF-5) was administered to evaluate the sexual performance.

Table 1.

Clinical presentation of the 20 men with non-penetrating penile injury at hospital admission.

\begin{tabular}{lc}
\hline Clinical picture & $\mathbf{2 0}$ cases (overall) \\
\hline Hematoma & $20(100 \%)$ \\
\hline Edema & $14(70 \%)$ \\
\hline Sound of "crack" & $12(60 \%)$ \\
\hline Pain & $20(100 \%)$ \\
\hline Deviation of the penis & $12(60 \%)$ \\
\hline Urethrorrhagia & $1(5 \%)$ \\
\hline
\end{tabular}

\section{Results}

Overall, MRI and CDU diagnosed 20/20 (100\%) and $12 / 20(60 \%)$ fractures of the tunica albuginea, respectively. In detail, CDU detected 11/15 (73\%) fractures of the penis and in 8 of them the length of the rupture was underestimated (more than 5 millimeter "mm") if compared with surgical exploration. MRI diagnosed all the

\section{Figure 2.}

Ventral fracture of the tunica albuginea.

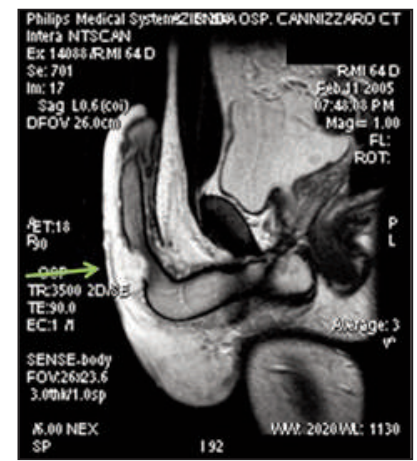

T2 weighted sagittal image pre-contrast

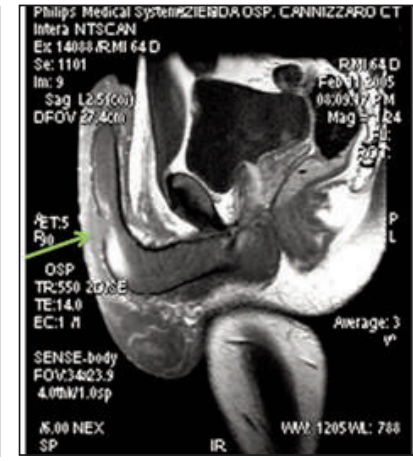

T1 weighted sagittal image post-contrast
Figure 1.
Diagnostic flow-chart for selection of treatment of penile trauma.

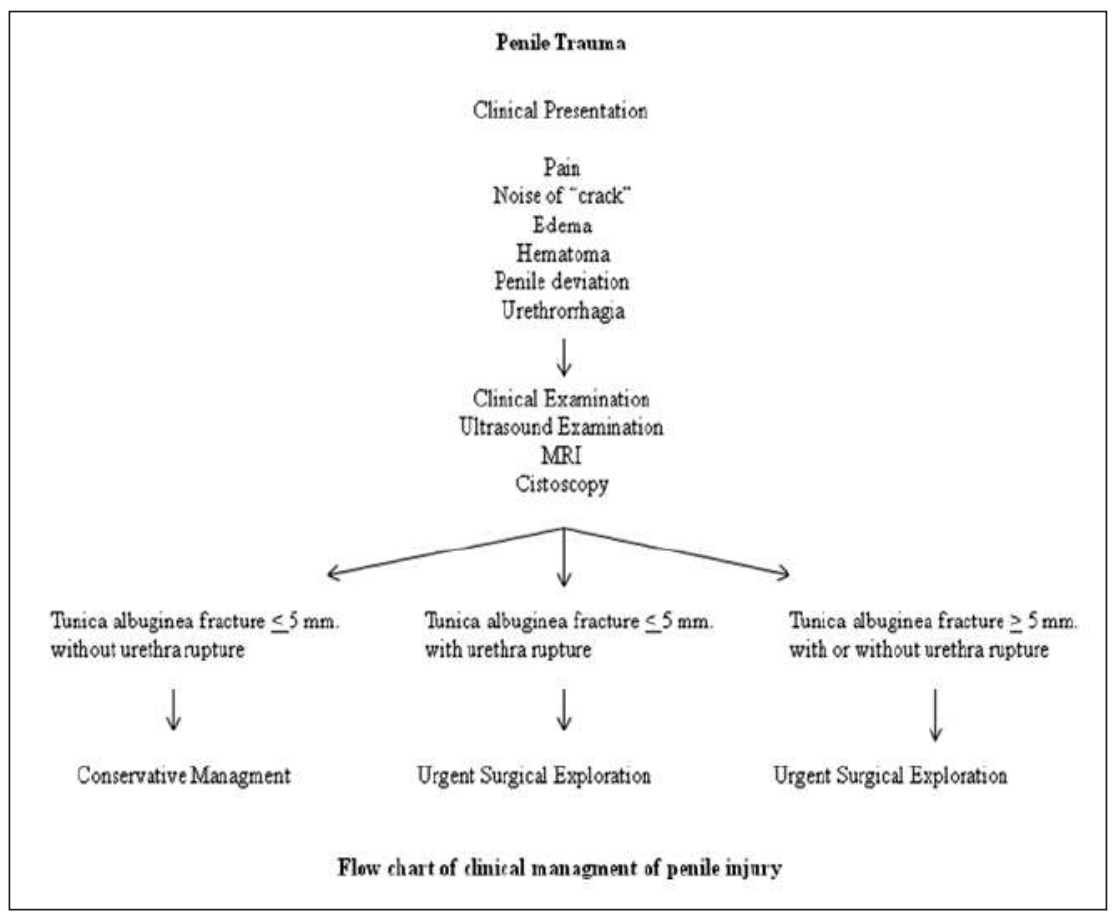

$15(100 \%)$ ruptures of the tunica albuginea showed by surgical exploration (Figure 2), but underestimated the length of the lesions in 9/15 (60\%) cases; conversely, in $6 / 15(40 \%)$ cases the extension of the lesion was superimposable or overestimated. In addition, MRI detected $1 / 2$ lesion (50\%) of the corpus spongiosum (Figure 3); $15 / 20(75 \%)$ underwent surgery within 24 (12 cases) or 36 hours ( 3 cases) from the trauma; in all the cases, a

\section{Figure 3.}

Fracture of the penis with corpus spongiosum involvement.

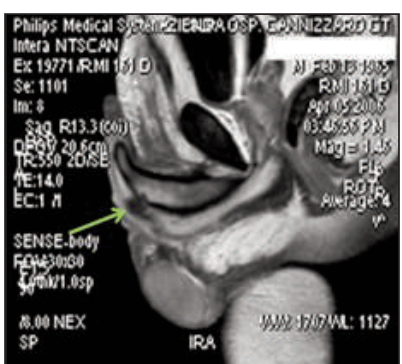

T1 weighted sagittal image pre-contrast

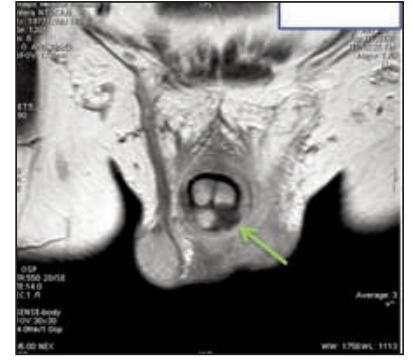

T1 weighted coronal image post-contrast

\section{Table 2.}

Location and side of the tunica albuginea rupture in the 15 patients submitted to surgical exploration.

\begin{tabular}{|lcc|}
\hline Side of the trauma & Number of patients & $\%$ \\
\hline Latero-dorsal & 2 & 13.3 \\
\hline Latero-ventral & 13 & 86.6 \\
\hline Bilateral & 2 & 13.3 \\
\hline Distal & 1 & 6.6 \\
\hline Middle of the penis & 9 & 60 \\
\hline Proximal & 5 & 33.3 \\
\hline Urethral involvment & 2 & 13.3
\end{tabular}


Table 3.

Imaging, surgical data, complications and functional results in the 15 patients submitted to surgery.

\begin{tabular}{|c|c|c|c|c|c|c|c|c|c|c|c|}
\hline \multirow{2}{*}{$\begin{array}{l}15 \text { patients } \\
\text { (overall) }\end{array}$} & \multicolumn{3}{|c|}{ CDU } & \multicolumn{3}{|c|}{ MRI } & \multicolumn{3}{|c|}{ Surgery } & \multirow{2}{*}{$\begin{array}{c}\text { Complications } \\
\text { n }(\%)\end{array}$} & \multirow{2}{*}{$\begin{array}{l}\text { IIEF-5 } \\
\text { score }\end{array}$} \\
\hline & $\mathbf{n}$ & $(\%)$ & $\mathrm{cm}$ & $\mathbf{n}$ & $(\%)$ & $\mathrm{cm}$ & $\mathrm{n}$ & $(\%)$ & $\mathrm{cm}$ & & \\
\hline Right side & 6 & 40 & $1-2$ & 6 & 40 & $1.5-2$ & 8 & 53.4 & $1-2.8$ & $\begin{array}{c}1(6) \\
\text { recunvatum } 30^{\circ}\end{array}$ & $\begin{array}{c}18 \\
\text { moderate ED }\end{array}$ \\
\hline Left side & 7 & 46.7 & $0.5-2$ & 6 & 40 & $1-2$ & 5 & 33.3 & $1-2.5$ & 0 & 0 \\
\hline Bilateral & 2 & 13.3 & 2.5 & 2 & 13.3 & $2-2.5$ & 2 & 13.3 & $2-3$ & $\begin{array}{c}1(6) \\
\text { coital pain }\end{array}$ & 22 \\
\hline Urethra & & 0 & & 1 & 6.6 & 2 & 2 & 13.3 & $2-3$ & $\begin{array}{c}1(6) \\
\text { coital pain }\end{array}$ & 22 \\
\hline
\end{tabular}

cases, respectively; moreover, a clinically significant hematoma was absent (Table 4).

MRI vs CDU demonstrated a diagnostic accuracy in the diagnosis of tunica albuginea rupture equal to 100 vs $50 \%$; at the same time, MRI vs CDU underestimated the real lentht of the rupture in $9(45 \%)$ and $12(80 \%)$ cases, respectively. All the patients were encouraged to have sexual activity at least 6 weeks later the trauma; median follow up was 5.7 months (range: 3-9). The IEFF-5 scores evaluated before and after the trauma of the penis are listed in Table 5 .
Table 4.

Imaging, complications and functional results in the 5 patients submitted to conservative management.

\begin{tabular}{|c|c|c|c|c|c|c|c|c|}
\hline $\begin{array}{l}5 \text { patients } \\
\text { (overall) }\end{array}$ & $n$ & $\begin{array}{l}\text { CDU } \\
(\%)\end{array}$ & $\mathrm{cm}$ & $\mathrm{n}$ & $\begin{array}{l}\text { MRI } \\
(\%)\end{array}$ & $\mathrm{cm}$ & $\begin{array}{c}\text { Complications } \\
n(\%)\end{array}$ & $\begin{array}{l}\text { IIEF-5 } \\
\text { score }\end{array}$ \\
\hline Right side & 0 & & & 1 & 20 & 1 & 0 & 24 \\
\hline Left side & 1 & 20 & 0.5 & 4 & 80 & 0.5 & 0 & 22 \\
\hline
\end{tabular}

\section{Table 5.}

Initial and post trauma sexual performance evaluated by the International Index Erectile Function-5 score (IIEF-5).

\begin{tabular}{|lcc|}
\hline IIEF-5 score & Before trauma (pts) & After trauma (pts) \\
\hline Normal (22-25) & $15(75 \%)$ & $15(75 \%)$ \\
\hline Minimal DE $(17-21)$ & $3(15 \%)$ & $3(15 \%)$ \\
\hline Minimal-moderate DE $(12-16)$ & $2(10 \%)$ & $2(10 \%)$ \\
\hline Moderate DE (8-11) & 0 & $1(5 \%)$ \\
\hline Severe DE (5-7) & 0 & 0 \\
\hline DE: rectile dysfunction; pts: patients. & & \\
\hline
\end{tabular}

large hematoma combined with edema of the penis was found. The site of the tunica albuginea injury is listed in Table 2; median length of the lesion was $19 \mathrm{~mm}$. (range: 5-30) with urethral involvement in 2 cases (13.3\%).

In 14/15 men (93.4\%) the penis was deviated controlaterally to the site of rupture.

All the patients submitted to surgical exploration underwent subcoronal approach, evacuation of hematoma and repair of the tunica albuginea using PDS (polydioxanone) $2 / 0$ in 5 cases e vicryl (polyglatin 910) 3/0 in 10 cases. At the end of surgery, an erection was induced to evaluate the presence of missed lesions and the absence of recurvatum. The urethral lesions were repaired using a slow absorption monofilament (monocryl 4/0 poliglecaprone 25) (Table 3); moreover, all the patients underwent antibiotic prophylaxis (a third generation cephalosporin combined with teicoplanin) and 2.5 days (range: 2-5 days) from surgery were discharged; 3/15 (20\%) men had minor complications following surgery: 1 case of hematoma treated conservatively, 1 case of pain during sexual activity and a case of penis recurvatum equal to $30^{\circ}$.

Five out of 20 patients (25\%) were hospitalized 48/96 hours from the trauma (average hospital stay was 2.5 days, range 1-5 days), and underwent conservative management, because MRI and CDU showed a lesion of the tunica albuginea $<5 \mathrm{~mm}$. in $5(100 \%)$ and $1(20 \%)$

\section{Discussion}

Literature data recommend early surgical exploration of penis in the presence of tunica albuginea rupture to improve a rapid resolution of pain and to reduce the risk of ED, corpora cavernosa fibrosis, symptomatic scars of the penis or recurvatum (5-9).

In the last years, the use of MRI has improved the diagnosis of penile injury; Saglam et al (10) reported in 122 patients a sensitivity and specificity of MRI equal to 100 with a positive (PPV) and negative predictive value (NPV) of 87.5 and $100 \%$, respectively. At the same time, Sokolakis et al. (11) on 43 patients showed a MRI sensitivity, specificity, NPV and PPV equal 100, 77.8, 100 and $90.5 \%$, respectively. Therefore, today, the use of MRI combined with dedicated protocols is strongly recommended in the clinical evaluation of penile injury (6-8) to plan the best therapeutic treatment for each patient (12-18). Despite the high accuracy, MRI is not always used in the evaluation of penile trauma because expensive and little available in emergency. On the other hand, although CDU allows an easy and repeatable morfological and functional evaluation of the penis its accuracy results lower in comparison with MRI (19).

In our series, MRI and CDU detected 100 (15/15 cases) vs $73 \%$ ( $9 / 15$ cases) of the penile fractures submitted to surgical exploration; conversely, among the five (25\%) patients who underwent conservative MRI and CDU diagnosed a lesion of the tunica albuginea $<5 \mathrm{~mm}$. in 100 ( $5 / 5$ cases) vs 20\% ( $1 / 5$ cases) of the patients, respectively. During the follow up nobody referred functional clinical complications; moreover, the IIEF-5 score was predictive of a normal sexual activity in the $75 \%$ of the cases resulting superimposable with the results obtained in men who underwent surgery.

Regarding our results some considerations should be done. First, our study is retrospective and refer to a limited number of patients. Secondly, we do not know the real extension of the tunica albuginea rupture in men submitted to conservative treatment. Third, our considerations are based upon a very low number of cases but could be expression of a greater number of minor penile trauma with good prognosis that in the "real life" could be missed because don't come to observation of the specialist. Finally, multicentric and multidisciplinary studies should be encouraged to improve the use of MRI in case of penile injury.

In conclusion, in our series, all the patients with a tunica albuginea rupture $<5 \mathrm{~mm}$. diagnosed by MRI and submit- 
ted to conservative management had a complete functional restitutio ad integrum. Anyway, multicentric and multidisciplinary studies should be encouraged to improve the imaging accuracy in the evaluation of penile injury.

\section{References}

1. Rodriguez D, Li K, Apoj M, Munarriz R. Epidemiology of Penile Fractures in United States Emergency Departments: Access to Care Disparities May Lead to Suboptimal Outcomes. J Sex Med. 2019; 16:248-56.

2. De Luca F, Garaffa G, Falcone M, et al. Functional outcomes following immediate repair of penile fracture: a tertiary referral centre experience with 76 consecutive patients. Scand J Urol. 2017; 51:170-75.

3. Anastasiou I, Anastasiou A, Katafigiotis I, et al. Isolated corpus spongiosum injury after sexual intercourse. Arch Ital Urol Androl. 2019; 90:295-296.

4. Kasaraneni P, Mylarappa P, Gowda RD, et al. Penile fracture with urethral injury: Our experience in a tertiary care hospital. Arch Ital Urol Androl. 2019; 90:283-287.

5. Özorak A, Hoşcan MB, Oksay T, et al. Management and outcomes of penile fracture: 10 years' experience from a tertiary care center. Int Urol Nephrol. 2014; 46:519-22.

6. Salonia A, Bettocchi C, Carvalho, et al. Guidelines Associates: EAU Sexual and Reproductive Health Guidelines 2020.

7. Yamaçake KG, Tavares A, Padovani GP, et al. Long-term Treatment Outcomes Between Surgical Correction and Conservative Management for Penile Fracture: Retrospective Analysis. Korean J Urol. 2013; 54:472-76.

8. Gamal WM, Osman MM, Hammady A, et al. Penile fracture: long-term results of surgical and conservative management. J Trauma. 2011; 71:491-93.
9. Al-Shaiji TF, Amann J, Brock GB. Fractured penis: diagnosis and management. J Sex Med. 2009; 6:3231-40.

10. Saglam E, Tarhan F, Hamarat MB, et al. Efficacy of magnetic resonance imaging for diagnosis of penile fracture: A controlled study. Investig Clin Urol. 2017; 58:255-60.

11. Sokolakis I, Schubert T, Oelschlaeger M, et al. The Role of Magnetic Resonance Imaging in the Diagnosis of Penile Fracture in Real-Life Emergency Settings: Comparative Analysis with Intraoperative Findings. J Urol. 2019; 202:552-57.

12. Cozzi D, Verrone GB, Agostini S, et al. Acute penile trauma: imaging features in the emergency setting. Radiol Med. 2019; 124:1270-80.

13. Esposito AA, Giannitto C, Muzzupappa C, et al. MRI of penile fracture: what should be a tailored protocol in emergency? Radiol Med. 2016; 121:711-18.

14. Guler I, Ödev K, Kalkan H, et al. The value of magnetic resonance imaging in the diagnosis of penile fracture. Int Braz J Urol. 2015; 41:325-28.

15. Rosi G, Fontanella P, Venzi G, et al. $3 T$ MR-guided minimallyinvasive penile fracture repair. Arch Ital Urol Androl. 2016; 88:68-69.

16. Koifman L, Barros R, Júnior RA, et al. Penile fracture: diagnosis, treatment and outcomes of 150 patients. Urology. 2010; 76:1488-92.

17. Pepe P, Panella P, Candiano G, et al. Partial priapism secondary to idiophatic segmental thrombosis of corpora cavernosa. Arch Ital Urol Androl. 2012; 84:101-03.

18. Pennisi M, Grasso Leanza F, Panella P, Pepe P. La rottura traumatica del pene. Caso clinico e revisione della letteratura. Contraccezione Fertilità Sessualità. 1992; 19:327-29.

19. Dell'Atti L, Scarcella S, Argalia G, et al. Rupture of the cavernous body diagnosed by contrast-enhanced ultrasound: Presentation of a clinical case. Arch Ital Urol Androl. 2018; 90:143-144.

\section{Correspondence}

Paolo Panella, MD (Corresponding Author)

ppanella5@gmail.com

Pietro Pepe, MD

Michele Pennisi, MD

Urology Unit - Cannizzaro Hospital

Via Messina 829, Catania (Italy) 